\title{
Climate Change and Mental Health: \\ New Model of Managing Mental Health Illness Resulting From Climate Change Events. Rwanda Perspective
}

\author{
Noel Korukire $^{1 *}$, Laura Bozzi ${ }^{2}$, Gilbert Banamwana ${ }^{3}$, Liliane Birasa ${ }^{4}$, Marie Claire Ineza ${ }^{5}$ Liberatha Rumagihwa ${ }^{6}$, \\ Emelyne Umutoni Cishahayo ${ }^{6}$, Isabelle Kayitesi ${ }^{7}$, Memunat Oyiza Akanbi ${ }^{8}$ \\ ${ }^{1}$ University of Rwanda, College of Medicine and Health Sciences, Environmental Health Sciences, Kigali, Rwanda \\ ${ }^{2}$ Department of Health, Rhode Island, United States \\ ${ }^{3}$ University of Rwanda, College of Medicine and Health Sciences, Mental Health, Kigali, Rwanda \\ ${ }^{4}$ American Refugee Committee, Kigali, Rwanda \\ ${ }^{5}$ University of Rwanda, College of Medicine and Health Sciences, Dentistry, Kigali, Rwanda \\ ${ }^{6}$ University of Rwanda, College of Medicine and Health Sciences, Nursing, Kigali, Rwanda \\ ${ }^{7}$ University of Rwanda, College of Medicine and Health Sciences, Medical Imaging, Kigali, Rwanda \\ ${ }^{8}$ Federal University of Technology, Department of Urban and Regional Planning, Nigeria
}

Corresponding author: Noel Korukire, College of Medicine and Health Sciences, University of Rwanda, Remera Campus, 11 KG Avenue 47, P.O. Box 3286 Kigali, Email: koranoe1980@gmail.com

\begin{abstract}
Hazards resulting from climate change jeopardize human in one way or another. Annually countless deaths, physical injuries, and the collapse of houses, among other consequences, are reported as negative effects associated to climate change events. There is no doubt that these effects are followed by mental health problems which requires the continuation of care after the emergency situation. This paper aimed at highlighting how climate change hazards in Rwanda might be followed by unidentified mental health illness, and proposed a model for proper management. The authors reviewed different literatures to inform their views about the issue and appreciate the efforts being done by the Government to manage immediate mental health problems resulting from climate change hazards for the victims. The authors suggested the need for the continuation of mental health care services after an emergency and that these services be provided by Community Health Workers who live day to day with victims. This will benefit not only the victims but also other people who might be having mental health issues within the community. The Authors recommend further research to document the impact of climate change on mental health and magnitude of the problem in Rwanda.
\end{abstract}

Keywords: Climate change, Hazards, Mental Health

\section{Background}

Climate change is defined as long-term shifts in weather conditions and patterns of extreme weather events. [1]The main cause of climate change is linked to the greenhouse gas emissions resulting in the consumption of fossil fuel and natural activities. [2] Climate change events such as floods, heat waves, landslides, sea level raise and others have caused negative impacts on humans. These events contribute to the occurrence of new cases of diseases and the multiplication of existing health threats.[1,2]

Some of these health problems that climate change is likely to cause are physical injuries,malnutrition, water associated diseases and social isolation due to displacement of the people amongst others. The World Health Organization revealed that in 2003, Europe recorded more than 70.000 deaths occurrencelinked to the heat waves and more than 60.000 deaths also occurred in developing countries due to hazards resulting from climate change.[3] This organization estimates that between 2030 and 2050, climate change will be responsible for 250000 additional death each year.[3]

In the next decades, these negative effects will continue to occur and will jeopardize the wellbeing and health of a significant number of people worldwide.[4] The United States Environmental Protection Agency indicates that all American states are facing theproblem resulting from climate change. For instance in Rhode Island, sea level rise is occurring, and if these changes in climate patterns continues, it may results to flooding which have an adverse effects on human and ecosystems'.[5]It is not only the United State of America which is concerned by climate change issues rather it is a global concern. [6] Research and reports on climate change effects on health tend to focus only on physical injuries, incidence of acute and chronic respiratory conditions such as asthma,vector-borne diseases carried by insects; and 
water related diseases such as diarrhea, cholera amongst others. Risks to mental health are less addressed,[7] and yet the World Health Organization (WHO) defines health as "a state of complete physical, mental and social wellbeing and not merely the absence of disease or infirmity".[8] Mental health issues such as anxiety, trauma, post trauma stress and depression among the health problems that climate change is likely to cause. It has negativeimpacts on thewellbeing of not only the affected individuals but also the entire society. Therefore mental health problems resulting from climate change and their management requires extra attention to ensure the wellbeing of the society; there is no health without mental health. [9] In this personal view, the authors highlight how climate change hazards in Rwanda might be followed by unidentified mental health illness, and propose a model for proper management of the menace.

\section{Impact of climate change in Rwanda}

Rwanda is not exempted from hazards resulting from climate change. These hazards affect many people in different ways. Since the year 2016, the connection between the City of Kigali and South by the main road Kigali-Muhanga(RN1) was broken due to floods at the Nyabarongo River, where the road was closed in period of 4 days due to much water on the road.At the same time, the connection between the north Province and the city of Kigali via main road Kigali-Musanze (RN4) was also broken due to landslides in the Gakenke and Rulindo Districts.

Hazards of this sort have affected people nationwide, though the magnitude of the problem is not the same in all districts. In 2017, 82 people reportedly died, 151 people had injuries, 5,802 houses were damaged, $5227 \mathrm{Ha}$ of crops were also damaged and 49 bridges were destroyed.[10] Every year impacts are reported, including: deaths and physical injuries; damage to infrastructure such as schools, health facilities, and electrical installations; pollution of water bodies leading to water borne diseases; loss of crops; and damage to housing due to the floods, land slide, or thunderstorms. [11] There is no doubt that these deaths, the collapse of houses which leave people homeless, as well as loss of crop, and loss of home items are being followed by psychological or mental health problems. These problems are not being identified and followed up.

\section{Climate change and mental health}

The ministry in charge of disaster management and refugees affairs in Rwanda projected that in the year 2016 alone, climate change extreme events would affect around 148 health facilities and 882 schools, 20.000 of people would become homeless, about 5000 pupils would not be able to attend schools, and 500 deaths and 2000 injuries wouldoccur.[11]Apart from known health problems associated to climate change hazards, there is no doubt that mental health is another health challenge which will happen after disasters. Louise et al(2014) demonstrated the relationship between climate change hazards and mental health, findings revealed that" "Climate change may affect mental health directly by exposing people to trauma". [7] Posttraumatic stress, anxiety and depression are the common mental health issues that follow disasters.[12] A study conducted after Hurricane Katrina in 2005 found that, several months after the hurricane, $49.1 \%$ of peoplein New Orleans city, Louisiana State and $26.4 \%$ in other affected areas had been diagnosed with a mental health disorder.[12] Paxson et al(2013)also conducted a study in the City of New Orleans, finding that $32 \%$ of respondents confirmed that theyexperienced trauma because one or more member(s) of their families or friends passed away as aresult of hurricane.[13] Evidences from other literature indicates that effects emanating from climate change such as going without food or water after disaster, losing a friend, parent or relatives may predict the long-term mental health struggle.[14]

A study conducted in Gulf Coast of the United States showed that mental health disorders may decline after disasters but they persist among vulnerable groups, [15] at least for a period between 43 to 54 months after disasters. [13] This may lead to the increase of suicides mortality rate.[7] Paxson et al(2013) in their study revealed that home damage was an important predictor of chronic post-traumatic stress symptoms.[13] Moreover, these mental health problems has negative health effects resulting from climate change or from other reasons which contribute to the occurrence of communicable and non-communicable diseases.[7] Neuropsychiatric disorders contribute to $14 \%$ of global burden diseases. [9] Studies shows that there is a linkage between a state of having psychological and cardiovascular problems. [16] It is not only these non-communicable diseases which might be connected to mental health problem, but also communicable diseases. Literature shows that in recent years, there was an expansion of viral infectious diseases due to mood disorders or common anxiety.[17] Scholars have shown how depression might be accelerated to those who are $\mathrm{HIV}^{+}$and may affect about $30 \%$ of people who are under treatment.[17] The above literature indicate how mental health problems influence other health conditions of individuals. 


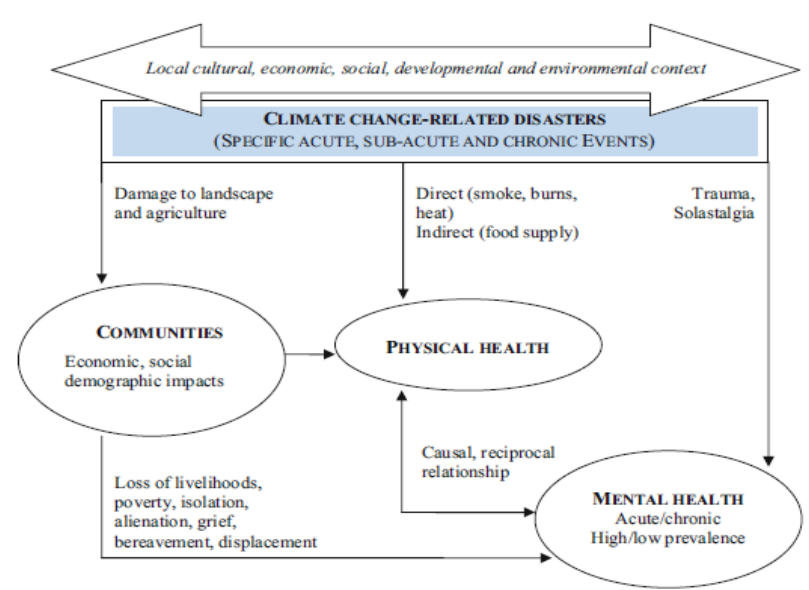

Source :[7].This figure illustrate the relationship between climate change and mental health

Thefigure above shows interconnection between climate change, communities, physical health of the people and mental health. In a case of climate change event such as flood, communities are likely to lose theirlivelihood assets which may lead to poverty, and displacement amongst others.

Physical health of people will be affected either directly such as collapse of houses due to landslides or indirectly by proliferation of vectors which in return become sources of a number of diseases. People in isolation due to displacement caused by either floods or drought may develop mental health disorder like stress, depression which may also lead to suicides. In addition, human who lose their social or human capital due to climate change events may also develop mental health problem.

\section{Efforts made to respond manage negative impacts of climate change hazards in Rwanda}

Managing risks resulting from climate change is crucial due to the irreversible threats climate change causes. [18] Various efforts are being made at all levels from international to local level to respond to the hazards that climate change is likely to bring. In the Rwandan context, a National preparedness and response plan for el-Nino effects was established in 2015. Provision of psychological healthcare to the victims is one of the activities planned. However, there is no plan as regards to following up with the victims, thoughdirectives were given by the healthcare system in Rwanda that mental health services should be provided at the health centre level.[19] It may be difficult for thoseassociated with mental health problems resulting from climate change extreme events to visit a health centre for services due to lack of knowledge about mental health signs ,symptoms and implicationsor they may even feel as it is normal.

\section{Proposed new model for managing mental health problem resulting from climate change}

It has been mentioned above that in the structure of Rwandan healthcare system, mental health nurses and psychologists are located at the health centres,[19] and that this does not fully serve the needs of those in need of mental health care services. Therefore, the authors proposed a model in which a trained Community Health Worker based at community level may use to assist the victims. The Community Health Worker should be equipped with basic mental health skills and knowledge for easy identification ofthose in need of mental health services after extreme eventsand make a follow up to ensure the continuity of care in his or her community. They should also endeavor to report cases as well, since mental health problems may persist among victims for a period of years.[13] In case the situation is complicated she/he may contact a trained mental health nurse for advanced assistance and management.Moreover, this may contribute to meeting the guidelines of the World Health Organization, which recommends that mental health services be provided at the community level: "Majority of patients requiring mental health care should bave the possibility of being treated at community level.'"[20]

\section{Conclusion}

The authors of this paper aimed to highlighthow climate change hazards in Rwanda might be followed by unidentified mental health illness, to propose a model for proper management, and to provide the authors' outlook. The relationship between climate change hazards and mental health highlighted in this paper is that the collapse of houses which make people homeless, loss of crops, damage of belongs, and deaths might be followed by the situation of anxiety, stress and depression among others which may lead to bad health outcomes. Authors also mentioned some efforts being made by the Rwandan government such as provision of emergency care including psychological care for victims, provision of domestic materials and financial assistance in burial ceremonies. However, there is a need for continuation of mental health services which may serve not only those victims of hazards resulting from climate change but also others who might have a preexisting mental illness. If the proposed model is accepted, it may contribute to a better management of mental health illness that may occur in our community. This paper then recommends further research to document the impact of climate change towards mental health and magnitude of the problem in Rwanda.

\section{Acknowledgement}

Thanks to One Health leaders who inspired me to think about the relationship between climate change and health. 


\section{Conflict of interest}

All authors declare no competing interest

\section{Contributors}

N.K. wrote the first draft. Other authors provided critical input and searching literature to respond to author's comments

\section{References}

1. Wu X, Lu Y, Zhou S, Chen L, Xu B. Impact of climate change on human infectious diseases: Empirical evidence and human adaptation. Environ Int. The Authors; 2016;86:14-23.

2. National Institute of Health. Climate Change and Human Health. 2016; avaialble from :https://www. niehs.nih.gov/health/materials/climate_change_ and_human_health_508.pdf

3. WHO. Climate change and Health. 2018 ;Available from :http://www.who.int/news-room/factsheets/detail/climate-change-and-health

4. Costello A, Abbas M, Allen A, Ball S, Bell S, Bellamy $\mathrm{R}$, et al. Managing the health eff ects of. Lancet. 2009;373.

5. EPA. What Climate Change Means for Rhode Island. 2016; available from:https://19january2017s napshot.epa.gov/sites/production/files/2016-09/ documents/climate-change-ri.pdf

6. Berhe DH. Climate Change Adaptation and Mitigation Measures in Ethiopia Climate Change Adaptation and Mitigation Measures in Ethiopia. 2014;
7. Louise H, Kathryn B. Climate change and mental health: A causal pathways framework Climate change and mental health: a causal pathways framework. 2010;

8. WHO. A glossary of terms for community health care and services for older persons. 2004; Avaialble from :http://www.who.int/kobe_centre/ageing/ ahp_vol5_glossary.pdf

9. Martin Prince, Vikram Patel SS. No health without mental health. Lancet. 2007; Available from:

10. MIDIMAR. Disaster effects situation 2017. 2018. Avaialble from:http://midimar.gov.rw/uploads/ tx_download/Disaster_2017.pdf

11. MIDMAR. National preparedness and response plan for 2015 el-nino effects in Rwanda. Kigali; 2015.

12. Jonathan A. Climate Change Challenges and Opportunities for Global Health.Available from: http:// citeseerx.ist.psu.edu/viewdoc/download?d oi $=10 \cdot 1 \cdot 1 \cdot 648.4937 \& \mathrm{rep}=$ rep1\&type $=$ pdf

13. Paxson C, Fussell E, Waters M. Five Years Later: Recovery from Post Traumatic Stress and Psychological Distress Among Low-Income Mothers Affected by Hurricane Katrina. Am J Hypertens. Avaialble from :https://www.ncbi. nlm.nih.gov/pmc/articles/PMC3286602/pdf/ nihms339629.pdf 2013;74:150-7.

14. AAAS. Science. 2018 Mar;970-9.

15. H.Norris F. Looking for resilience: Understanding the longitudinal trajectories of responses to stress. Available from:https://www.ncbi.nlm.nih.gov/ 